\title{
TERHAMBATNYA PROSES HIBOB JANGKAR PADA MT. ETERNAL II
}

\author{
Firnanda, A.D. ${ }^{1}$, Ndori, $\mathbf{A}^{1^{*}}$ \\ ${ }^{1}$ Program studi Nautika, Politeknik Ilmu Pelayaran Semarang \\ Jl. Singosari 2a Semarang 50242 \\ Telp. (024) 8311527 Fax. (024) 8311529 \\ *Email: dalifgapn@gmail.com
}

\begin{abstract}
Abstrak
MT. Eternal Oil II berlabuh jangkar di Muntok, Selat Bangka terjadi suatu permasalahan, di antaranya Kelasi jaga saat itu lalai saat mengisi angin di pompa hidrolik, mengakibatkan tidak maksimalnya kekuatan windlass jangkar, sehingga jangkar kiri tidak dapat di hibob. Ini mengakibatkan kapal tidak dapat beroperasi dan perusahaan mengalami kerugian. Metode penelitian yang digunakan adalah metode deskriptif kualitatif. Metode pengumpulan data berupa da yang diperoleh melalui observasi dan wawancara. Data sekunder diperoleh melalui studi dokumentasi dan kepustakaan. Hasil penelitian menunjukkan terjadinya kelebihan tekanan angin pada tabung mesin pompa hidrolik yang mengakibatkan terhambatnya proses hibob jangkar kapal ketika akan memasuki alur sungai Musi menuju Palembang adalah kurangnya pengetahuan Kelasi jaga akibat yang dapat ditimbulkan atau prosedur yang dilakukan saat akan mengisi angin pada tabung mesin pompa hidrolik, kurangnya komunikasi antara awak kapal, kurangnya perawatan pada mesin pompa hidrolik dan mesin windlass sebelah kiri pada kapal MT. Eternal Oil II.
\end{abstract}

Kata kunci: hibob jangkar, pompa hidrolik, windlass

\section{PENDAHULUAN}

Berlabuh jangkar ialah mengikat kapal pada dasar perairan agar kapal tidak hanyut karena arus atau angin. Kegiatan berlabuh jangkar sering dijumpai berbagai macam permasalahan, baik berasal dari alam maupun kesalahan sumber daya manusia (SDM). Permasalahan dari alam contohnya laut, arus, angin. Sedangkan permasalahan dari SDM yaitu kurangnya pengetahuan serta kelalaian crew kapal saat proses berlabuh jangkar.

MT. Eternal Oil II saat berlabuh jangkar di Muntok, Selat Bangka tanggal 19 Maret 2019 terjadi suatu permasalahan, di antaranya Kelasi jaga saat itu lalai saat mengisi angin di pompa hidrolik. Hal tersebut mengakibatkan tidak maksimalnya kekuatan windlass yang menyebabkan jangkar kiri tidak dapat dihibob dan kapal tidak dapat beroperasi, sehingga perusahaan mengalami kerugian. Seharusnya pelaksanaan berlabuh jangkar dilaksanakan secara efektif, efisien, aman, dan terkendali. Arti dari terkendali disini yaitu semua komponen terkait pelaksanaan berlabuh jangkar dapat dikendalikan dengan baik.
Mulai dari kesiapan semua peralatan sampai dengan semua crew kapal harus mengerti tugasnya masing-masing. Oleh karena itu, para perwira kapal harus memberikan informasi serta pengetahuan dasar kepada seluruh crew yang bertugas agar kelalaian crew kapal yang dapat mengakibatkan banyak kerugian tidak terjadi lagi.

\section{LANDASAN TEORI}

Jangkar merupakan alat labuh yang mempunyai bentuk dan berat khusus yang akan diturunkan ke kedalaman air sampai dengan dasar sehingga kapal sangat terbatas pergerakannya dengan posisi jangkar dan panjang rantai yang diturunkan. Hal ini untuk menahan supaya kapal tidak bergerak dan tetap dalam posisinya (2011,http://www.maritimeworld.web.id). Jenis jangkar di bedakan menjadi dua kategori yaitu jenis jangkar berdasarkan peletakannya dan jenis jangkar berdasarkan bentuk dan fungsinya.

1. Menurut peletakannya: jangkar haluan, jangkar arus, jangkar cemat. 
2. Menurut fungsi dan bentuknya: Scream anchor, jangkar AC14, hall, spek, Damforth, Stevin.

Bagian-bagian jangkar pada umumnya yaitu:

1. Arm (lengan), merupakan bagian dari jangkar yang membentang dari ujung jangkar (crown) akhir, batang jangkar (shank) dan menghubungkan ke telapak jangkar (palm).

2. Band, adalah logam melingkar yang mengamankan dua bagian dari stok kayu secara bersama-sama dengan batang jangkar (shank).

3. Bill, adalah akhir dari lengan jangkar (palm).

4. Crown (mahkota), merupakan ujung runcing akhir dari jangkar (shank) dengan lengan.

5. Eye (mata), merupakan lubang di akhir batang jangkar (shank) tempat cincin terpasang.

6. Fluke, adalah bentuk sekop bagian dari lengan jangkar ( $\mathrm{arm}$ ) yang digunakan untuk menggali dasar laut dalam mengamankan kapal.

7. Palm, merupakan bagian datar paling atas dari sekop (flake).

8. Ring, adalah bagian jangkar dimana tali atau rantai melekat dan menghubungkan jangkar ke kapal.

9. Shank, adalah batang tegak dari jangkar. Stock, merupakan lintas bar jangkar yang memungkinkan sekop pada jangkar (flake) dapat menggali dasar laut.

Kapal yang berlabuh jangkar bisa terjadi larat, yaitu suatu keadaan dimana rantai kapal tertahan dan jika rantainya kemudian tegang arus artinya rantai terseret atau tidak makan (jangkar kapal larat). Jenis dasar perairan dan kekuatan arus biasanya menjadi faktor utama penyebab jangkar larat, sehingga memilih tempat berlabuh jangkar (anchorage) yang tepat dapat mempengaruhi terjadinya jangkar larat. Anchorage biasanya memiliki kondisi yang aman untuk jangkar dalam perlindungan dari kondisi cuaca, dan bahaya lain.
Proses berlabuh jangkar pada MT. Eternal Oil II yang pertama dilakukan yaitu pengisian angin pada tabung pompa hidrolik oleh Kelasi jaga. Selanjutnya jika sudah terisi, hidupkan mesin windlass dan buka stopper yang mengunci rantai jangkar, kemudian operasikan mesin windlass untuk berputar menurunkan rantai jangkar. Sebaliknya untuk menghibob jangkar, mesin windlass dioperasikan dengan berputar mengangkat rantai jangkar. Windlass adalah salah satu peralatan kapal yang penting untuk kegiatan operasional saat kapal akan berlabuh jangkar. Ketentuan pemasangan windlass diatur dalam peraturan klasifikasi (Classification Rules and Regulation), Biro Klasifikasi Indonesia (BKI), Det Norske Veritas (Norwegia), Germanischer Lloyd (Germany), American Beurau of shipping (USA), Lloyd Register (Inggris), Beurau Veritas (France). Selain diterapkan peraturan klasifikasi, ketentuan terhadap pemasangan alat bantu kerja pada windlass juga diterapkan syarat dalam peraturan SOLAS (Safety of Life at Sea) Chapter II-1 yang mengatur syarat perlengkapan kapal untuk keselamatan di kapal.

\section{METODE}

Lokasi penelitian ini yaitu di atas kapal MT. Eternal Oil II. Adapun waktu pelaksanaan penelitian selama 1 tahun 1 hari, terhitung mulai tanggal 24 Agustus 2018 sampai dengan 25 Agustus 2019.

Metode yang digunakan penulis yaitu deskriptif kualitatif. Metode ini digunakan dalam suatu keadaaan atau masalah yang dialami oleh subjek penelitian dengan memanfaatkan berbagai metode ilmiah. Bentuk data kualitatif yang dihasilkan berupa gambar, kata-kata, bahasa, dan kejadian. Oleh karena itu, untuk memperoleh data-data tersebut, penulis melakukan observasi, wawancara dan dokumentasi. Obeservasi dilakukan dengan cara mengamati objek secara langsung di kapal MT. Eternal Oil II. Sedangkan wawancara dilakukan dengan bertanya 
secara langsung dengan Mualim 1, Mualim 3, dan Bosun. Serta dokumentasi dilakukan dengan cara mengabadikan beberapa dokumen berbentuk foto guna mendukung kegiatan penelitian.

\section{HASIL DAN PEMBAHASAN}

Penggunaan mesin bantu pompa hidrolik yang sesuai dengan Standard Operation Procedure (SOP) akan menambah kinerja mesin yang signifikan dan menambah umur mesin. Selain itu juga berpengaruh pada saat memutar mesin windlass yang akan menaikan rantai jangkar agar proses hibob jangkar dapat berjalan dengan lancar dan tidak menghambat olah gerak kapal. Perawatan yang teratur pada pompa hidrolik sangat diperlukan untuk memahami bagaimana cara kerja mesin tersebut baik komponen utamanya maupun komponen pembantu.

Faktor utama penyebab terhambatnya proses hibob jangkar yang disebabkan menurunnya kinerja mesin pompa hidrolik yaitu perawatan yang tidak sesuai Standart Operational Procedure (SOP) dan kurangnya pengetahuan awak kapal terhadap tugas-tugasnya. Disini ditekankan pada Kelasi jaga yang bertugas mengisi angin pada pompa hidrolik untuk olah gerak kapal. Berikut adalah keempat faktor kemungkinan permasalahan tersebut.

\section{Man (Manusia atau Pekerja)}

Setiap crew kapal memiliki keharusan untuk memahami Standart Operational Procedure (SOP) sebelum menaiki kapal, supaya mengurangi resiko terhadap kejadian yang tak terduga. Namun, pada kenyataannya, crew kapal tidak mengikuti SOP yang diajarkan dengan baik, sehingga pengetahuan awak kapal akan perawatan mesin pompa hidrolik masih kurang. Perawatan yang baik akan membuat mesin bantu pompa hidrolik berfungsi dengan baik dan memenuhi persyaratan yang ditetapkan. Kurangnya pemahaman dan kepedulian kepada prosedur-prosedur yang ada, membuat perawatan pada mesin bantu pompa hidrolik menjadi kurang optimal. Pada akhirnya terjadi penurunan tenaga yang mengakibatkan kurang maksimalnya putaran pada mesin windlass. Hal tersebut terjadi karena kurangnya perawatan fisik pada permesinan dek kapal yang dilakukan oleh Chief Officer. Perawatan fisik pada permesinan dek kapal tidak dilakukan secara rutin dan tidak mengikuti prosedur pada manual book. Hal ini berdampak sangat buruk karena akan menguras waktu, tenaga, dan biaya ketika mesin pompa hidrolik mengalami kerusakan. Pentingnya pengetahuan dan pengalaman awak kapal dalam melakukan perawatan pada mesin bantu pompa hidrolik sangat berpengaruh terhadap kinerja mesin bantu windlass. Dalam hal ini sesuai dengan hasil wawancara yang peneliti lakukan dengan narasumber, bahwasanya awak kapal melakukan perawatan pada mesin bantu pompa hidrolik hanya berdasarkan kebiasaan dan pengalaman yang sudah dilakukan tanpa mengamati atau mengikuti prosedur yang terdapat dalam manual book. Awak kapal masih berpegang pada paradigma lama yang mengatakan biasanya tidak apa-apa. Sedangkan untuk cara kerja pada Standard Operational Procedure (SOP), cara kerja dan perawatan permesinan harus berdasarkan dari manual book mesin itu, walaupun secara umum hampir sama atau mungkin sama, namun tetap saja setiap mesin mempunyai karakter masing-masing, dan hal ini yang sering tidak diperhatikan oleh awak kapal.

\section{Machine/tools}

Dalam proses olah gerak kapal, hibob jangkar maupun let go jangkar diperlukan sistem yang mendukung supaya pengoperasian dapat berhasil. Sistem peralatan kapal juga berdampak sangat besar pada pengoperasian olah gerak kapal saat hibob jangkar maupun let go jangkar. Sehingga perlu adanya perawatan dan pengecekan rutin pada sistem peralatan di atas kapal. Dari hasil penelitian, penulis menemukan awak kapal tidak melaksanakan 
prosedur perawatan mesin bantu pompa hidrolik. Pompa hidrolik adalah suatu mesin bantu yang terdiri dari komponen-komponen yang di dalamnya berisi minyak atau oil dan udara. Pompa hidrolik yang berguna untuk memutar mesin bantu windlass pada saat proses hibob jangkar. Yang dilakukan crew kapal pada saat akan mengoperasikan pompa hidrolik ialah melihat indikator antara udara dan minyak, apakah sudah sesuai pada garis tanda yang sudah diberikan pada tabung pompa hidrolik atau belum. Jika belum maka awak kapal yang bertugas ialah kelasi jaga mengisikan udara pada tabung pompa hidrolik hingga sesuai dengan tanda pada indikator tersebut. Jika tekanan udara melebihi batas tanda pada indikator, maka tenaga yang dihasilkan pompa hidrolik menurun sehingga tidak dapat memutar mesin bantu windlass.

\section{Metode}

Dalam melaksanakan pekerjaan di atas kapal, komunikasi merupakan hal yang sangat mutlak dilakukan agar pekerjaan dapat berjalan secara optimal. Berdasarkan hasil penelitian di atas kapal, penulis menemukan bahwa perawatan mesin bantu pompa hidrolik tidak sesuai dengan Standard Operational Procedure (SOP) dikarenakan kurangnya komunikasi antara Mualim 1 dengan awak kapal terhadap pekerjaan pemeliharaan mesin bantu pompa hidrolik. Sesuai dengan prosedur yang terdapat di manual book, Mualim 1 tidak selalu melakukan safety meeting ataupun memberikan informasi tentang bagaimana Standard Operational Procedure (SOP) yang benar kepada awak kapal mengenai perawatan mesin bantu pompa hidrolik di atas kapal, sehingga setiap awak kapal kurang memahami SOP yang ada. Perawatan mesin bantu pompa hidrolik sendiri juga bertujuan meminimalisir kerusakan mesin tersebut. Kurangnya komunikasi tentu mengakibatkan kurang optimalnya perawatan mesin bantu pompa hidrolik, sehingga dapat menyebabkan pompa hidrolik tidak dapat memutar mesin windlass, yang dapat menghambat olah gerak kapal, dan mempengaruhi keselamatan pelayaran di atas kapal MT. Eternal Oil II.

Berdasakan hasil observasi yang penulis lakukan di atas kapal, wawancara (Mualim 1, Mualim 3, dan Bosun) serta studi pustaka, terdapat beberapa dampak yang ditimbulkan dari macetnya mesin windlass saat proses hibob jangkar, yaitu: Rantai jangkar berhenti pada segel ke-2 saat proses hibob jangkar. Mesin bantu windlass berfungsi untuk keperluan mengangkat atau mengulurkan rantai jangkar dan juga tali-tali untuk keperluan olah gerak kapal. Mesin bantu pompa hidrolik berfungsi untuk memberikan tenaga agar mesin windlass dapat beroperasi sesuai kegunaannya, Jika diantara salah satu komponen mengalami kerusakan, maka akan menimbulkan suatu permasalahan terkait keamanan kapal, muatan, dan menghambat kelancaran proses olah gerak kapal. Oleh sebab itu, mesin bantu pompa hidrolik harus digunakan sesuai dengan prosedur yang ada serta dilakukan perawatan yang rutin dan berkala agar meminimalisir terjadinya kerusakan pada pompa hidrolik. Penulis menemukan adanya kelalaian awak kapal dalam melaksanakan tugasnya atau tanggung jawabnya. Kelalaian ini yang menyebabkan pompa hidrolik tidak dapat beroperasi dengan lancar atau dengan kata lain kinerja mesin bantu pompa hidrolik menurun. Hal itu dikarenakan seorang awak kapal atau disini sebagai kelasi jaga waktu itu tidak memperhatikan indikator di tabung pada saat melakukan pengisian angin atau udara ke dalam tabung pompa hidrolik yang sudah diberi tanda komposisi batas udara yang diisi dan minyak yang ada di dalamnya di kapal MT. Eternal Oil II.

Keterlambatan saat melakukan proses olah gerak masuk pelabuhan. Sebuah kapal memiliki berbagai macam peralatan yang berperan sebagai penunjang kelancaran operasional kapal yang dimana alat-alat tersebut memiliki fungsi masing-masing sebagai alat bantu kerja untuk 
mempermudah pekerjaan diatas kapal. Peralatan tersebut tentu memerlukan suatu perawatan yang rutin dan berkala sesuai ketentuan yang telah ditetapkan dalam Plan Maintenance System (PMS) dan menjalankan perawatan tersebut sesuai dengan Standard Operational Procedure (SOP) agar dapat menunjang kelancaran operasional kapal. Pada saat kapal MT. Eternal Oil II berlabuh di Muntok Selat Bangka, ketika itu kapal diberi perintah untuk One Hour Notice (OHN). Seluruh awak kapal bersiap untuk menjalankan OHN, ketika itu Kelasi jaga yang bertugas mengisi angin pada mesin bantu pompa hidrolik melaksanakan tugasnya tidak sesuai prosedur. Kelasi jaga mengisi angin melebihi garis batas yang sudah diberi tanda pada tabungnya, komposisi minyak dan udara yang sudah diperhitungkan dan ditetapkan. Namun, saat itu, Kelasi jaga tidak memberi tahu kepada anjungan bahwa pengisian angin telah melebihi batas yang ditentukan. Pada saat semua siap pada posisi standby masing-masing, saat Nakhoda memberi perintah memulai proses hibob jangkar yang pada waktu itu rantai jangkar 6 segel di atas air, pada awal hibob jangkar masih tidak ditemui gejala atau tanda-tanda akan adanya masalah. Namun pada saat rantai jangkar sampai pada segel ke-3, mesin windlass mulai mengalami gejala sering berhenti dan dapat berputar kembali namun semakin pelan, hingga pada saat rantai jangkar sampai pada segel ke-2 mesin windlass sudah tidak dapat berputar lagi, pada saat itu Nakhoda memberi perintah letgo jangkar 1 segel. Namun, saat dihibob kembali hal yang sama terjadi yaitu mesin windlass berhenti pada segel ke-2. Nakhoda sempat berfikir jika jangkar tersangkut pada dasar laut, lalu Nakhoda memerintahkan kapal mundur pelan sekali. Tentunya sudah melihat arah rantai jangkar, namun kapal pada saat itu bergerak mundur sambil tetap di hibob, dan hasil yang sama mesin windlass tetap tidak berputar pada posisi rantai jangkar sampai segel ke-2. Pada saat itu Nakhoda memutuskan untuk jangkar kembali di letgo dan memerintahkan Mualim 1 memeriksa apa sebenarnya sumber dari masalah tersebut. Pada saat dilakukan pengecekan pada mesin windlass tidak ditemukan kerusakan, lalu melanjutkan pengecekan pada mesin bantu pompa hidrolik, awalnya awak kapal tidak melihat indikator pada tabung, namun melakukan pengecekan apakah terjadi kebocoran pada pipa-pipa yang terhubung pada mesin bantu windlass, namun tidak juga ditemukan kebocoran. Pada saat melihat indikator tabung pompa hidrolik ternyata indikator angin melebihi batas yang ditentukan. Saat itu juga sumber masalah ditemukan dengan segera Mualim 1 melaporkan kepada Nakhoda dan langsung melaporkan kepada agen Pertamina bahwa kapal MT. Eternal Oil II tidak dapat melakukan olah gerak menuju alur sungai Musi menuju Palembang, dikarenakan mengalami kendala rantai jangkar tidak dapat dihibob lalu meneruskan dengan membuat berita acara sesuai prosedur.

Setelah kejadian tersebut, kapal MT. Eternal Oil II mengalami keadaan darurat karena terbatas dalam berolah gerak. Keadaan darurat adalah keadaan di luar keadaan normal yang terjadi di atas kapal yang mempunyai tingkat kecenderungan untuk dapat mengancam keselamatan jiwa manusia dan harta benda yang ada di atas kapal serta lingkungan dimana kapal tersebut mengalami musibah. Keadaan darurat yang terjadi di atas kapal diantaranya tubrukan, kandas, kebocoran, orang jatuh ke laut, kebakaran, dan pencemaran. Setiap kapal harus dapat mengatasi keadaan darurat dengan cepat dan tanggap untuk menghindari situasi krisis atau situasi yang terjadi di atas kapal sebagai akibat gagalnya mengatasi suatu keadaan darurat, dimana situasi tersebut sudah tidak dapat dikontrol, karena semua orang yang ada di atas kapal panik, cemas dan khawatir serta ingin selamat dari musibah (Purwantomo,2018). Sehubungan dengan teori tersebut maka diperlukan kesiapan dari seluruh mesin bantu maupun alat keselamatan di atas kapal 
untuk menanggulangi keadaan darurat yang memungkinkan dapat terjadi kapan saja, dimana saja serta dalam keadaan apa saja. Oleh karena itu perawatan terhadap alat-alat bantu harus dilakukan secara rutin dan berkala sesuai Standard Operational Procedure (SOP) yang ada, sehingga siap digunakan pada saat mengkeadaan darurat.

Upaya yang dilakukan untuk mengatasi macetnya mesin windlass karena kelebihan tekanan angin pada pompa hidrolik yang mengakibatkan terhambatnya proses hibob jangkar di MT. Eternal Oil II yaitu Nakhoda memberi perintah mundur pelan sekali yang bertujuan untuk membantu melepas jangkar jika tersangkut di dasar laut. Pada saat rantai jangkar sampai pada segel ke-2, sudah tidak dapat dihibob lagi. Padahal sudah dihitung dalamnya laut berarti jangkar dalam posisi up and down atau tegak lurus pada dasar laut. Namun saat itu saat mesin kapal mundur pelan sekali, kapal masih tetap bergerak mundur sambil terus dihibob dan mesin bantu windlass tetap tidak berputar dan kapal tetap bergerak mundur lalu Nakhoda memerintahkan stop engine. Setelah itu Nakhoda memerintahkan untuk di letgo kembali 6 segel di air dan mengadakan safety meeting dan membuat berita acara bahwa jangkar tidak dapat dihibob. Selain itu, Nahkoda mengunakan cara lain yaitu dengan menggunakan bantuan mesin windlass sebelah kanan. Mesin windlass sebelah kiri yang pada saat itu digunakan sebelumnya mengalami kerusakan sehingga tidak pernah digunakan. Namun, kondisi waktu itu mencoba mesin windlass sebelah kiri karena setelah dilakukan perbaikan. Kemudian jangkar dicoba untuk dihibob kembali menggunakan bantuan mesin windlass sebelah kanan. Pada saat itu, Masinis II mengambil alih pengoperasian. Langkah awal ulur tali tross dan dikaitkan ke rantai jangkar dengan pelan-pelan rantai mulai naik pelan. Setelah rantai jangkar sudah setengah segel di air dan melihat indikator pada tabung pompa hidrolik, tekanan angin sudah menurun sesuai garis tanda yang sudah diberikan, lalu mencoba menggunakan mesin windlass sebelah kiri dan hasilnya dapat berputar dengan normal hingga jangkar terangkat dengan baik.

\section{KESIMPULAN}

Berdasarkan hasil penelitian yang dilakukan penulis, maka dapat ditarik kesimpulan sebagai berikut: faktor yang menyebabkan terjadinya kelebihan tekanan angin pada tabung mesin pompa hidrolik yang mengakibatkan terhambatnya proses hibob jangkar kapal ketika akan memasuki alur sungai Musi menuju Palembang adalah kurangnya pengetahuan kelasi jaga akan sebab akibat yang dapat ditimbulkan atau prosedur yang dilakukan saat akan mengisi angin pada tabung mesin pompa hidrolik, kurangnya komunikasi antara awak kapal, kurangnya perawatan pada mesin pompa hidrolik dan mesin windlass sebelah kiri pada kapal MT. Eternal Oil II. Dampak yang ditimbulkan dari kurang optimalnya kerja mesin pompa hidrolik karena kelebihan tekanan angin dari komposisi yang sudah ditentukan dan diberi tanda adalah tidak dapat berputarnya mesin windlass sehingga tidak dapat menarik rantai jangkar dan kapal mengalami keterlambatan proses olah gerak; Upaya yang dilakukan untuk mengatasi terhambatnya proses hibob jangkar yang dikarenakan kurang optimalnya kerja mesin pompa hidrolik diatas adalah memberikan pengetahuan tentang sebab akibat dari pengoperasian perlatan bantu dan mesin bantu terhadap kelancaran olah gerak kapal dan keselamatan pelayaran.

\section{DAFTAR PUSTAKA}

Fathoni, Abdurrahmat, 2006, Metodologi Penelitian dan Teknik penyusunan Penelitian, Rineka Cipta, Jakarta.

Purwantomo, Agus Hadi, 2004, Emergency Procedure dan SAR, PIP Semarang.

Sugiyono, 2015, Metode Penelitian Pendidikan, Alfabeta, Bandung.

2011, https://www.maritimeworld.web.id 